\title{
Fetal interrupted aortik ark tip B'nin antenatal değerlendirilmesi
}

\author{
Antenatal evaluation of fetal interrupted aortic arch type B
}

\author{
Ali Babacan¹,Yaşam Kemal Akpak², Okan Özden', Selami Süleymanoğlu³, Ersin Öztürk4, \\ Ercüment Müngen ${ }^{1}$
}

\section{ÖZET}

Interrupted aortik ark (IAA), aortik kavisin iki komşu segmentinin anatomik olarak kesintiye uğradığı konjenital kalp hastalıklarının nadir görülen ama ciddi formlarından biridir. Fetal IAA'nın özelliklerine ve sonuçlarına ilişkin veriler sınırlıdır. Kesintinin olduğu yere göre tarif edilen üç tipi vardır. Konotrunkal anomalilerde, 4 odacık görüntüsü, 4 kapağın hepsi ve tüm damar çıkışları dahil olmak üzere obstetrik fetal anomali taramasındaki mevcut önerilerin hepsi normal izlenebilir. Prenatal ekokardiyografide IAA tanınmasının zor olsa da, anatomik bir dizi özellikler tanıyı kolaylaştırabilir. Biz, kliniğimize refere edilen IAA Tip B olgusunun özellikleri ve sonuçlarını literatür ışığında sunmayı amaçladık.

Anahtar kelimeler: Konjenital kalp defekti, dört boyutlu ultrason, fetal ekokardiyografi, interrupted aortik ark, prenatal tanı

\section{GíRiş}

İnterrupted aortik ark (IAA) aort kavsine ait asendan ve desendan aort arasında anatomik kesinti veya atrezi olarak tanımlanmaktadır. Nadir gözüken ancak postpartum yaşamdaki sistemik dolaşım için ciddi riskleri olan bir anomalidir [1]. Konjenital kap hastalıklarının (KKH) yaklaşık \%1,5'ini oluştururken, izlenme sıklığ ise 100.000 canlı doğumda 2' dir [2]. Üç tipi mevcuttur; kesinti olan bölge, Tip A'da sol subklavian arterin distalinde, Tip B'de sol karotis kommunis ve sol subklavian arterler arasında ve Tip C'de ise sol karotis kommunis ve innominate arterler arasındadır [3]. Genellikle Tip B vakalarında

\begin{abstract}
Interruption of the aortic arch (IAA) is a rare, severe form of congenital heart defect characterized by complete anatomical discontinuity between two adjacent segments of the aortic arch. The data on the features and outcomes of fetal IAA are limited. Three anatomical types have been described according to the site of interruption. The current recommendations for screening on the obstetric fetal anomaly scan include identification of a 4-chamber view, all 4 valves, and the outflow tracts, all of which can appear to be normal to the ultrasonographer in fetuses with conotruncal anomalies. Although the identification of IAA on a prenatal echocardiogram can be challenging, a number of anatomic features can facilitate the diagnosis. We aim to present the features and outcome of a case of IAA type $B$ referred to our centre in the light of literatures.
\end{abstract}

Key words: Congenital heart defect, four dimensional ultrasound, fetal echocardiography, interrupted aortic arch, prenatal diagnosis

arkus aorta gelişmemiştir. Çıkan aorta innominate arteri verdikten sonra sola yukarı doğru sol karotis arterle devam eder ve görüntüleme yöntemleriyle tipik olarak V görüntüsü elde edilir. Tip A vakalarda ise aortik ark kısmen gelişmiştir. İnnominate arter, sol karotis ve sol subklavian arter doppler ultrasonda tipik olarak W görünümü oluşturur [3]. Tip B en sik (\%84) izlenen, Tip C ise nadir (\%3) ve en fatal tipidir [4]. İzole tanı alması çok nadir (\%2) olup, genelde diğer kardiyak anomalilerle birlikte izlenir. $\% 90$ oranında ventriküler septal defekt (VSD) birlikteliği mevcut olup, atrial septal defekt, subaortik stenoz, biküspid aort kapağı, aortopulmoner pencere, büyük damar transpozisyonu, triküspit atrezisi

\footnotetext{
${ }^{1}$ GATA Haydarpaşa Ĕ̆itim Hastanesi, Kadın Hastalıklarl ve Doğum Kliniği, İstanbul, Türkiye

${ }^{2}$ Ankara Mevki Asker Hastanesi, Kadın Hastalıkları ve Doğum Kliniği, Ankara, Türkiye

${ }^{3}$ GATA Haydarpaşa Ĕ̆gitim Hastanesi, Çocuk Sağlı̆̆l ve Hastalıkları Kliniği, İstanbul, Türkiye

${ }^{4}$ GATA Haydarpaşa Eğitim Hastanesi, Radyoloji Servisi, İstanbul, Türkiye
}

Yazışma Adresi /Correspondence: Ali Babacan, 
ve çift çıkıșlı sağ ventrikül de dahil olmak üzere bir çok kalp anomalisiyle izlenebilir [2].

Duktal ark ile aortik arkı ayırmanın güçlüğü sebebiyle prenatal tanısı zor konan, genelde pospartum tanısı konabilen bir konjenital kalp hastalığıdır. Konotrunkal kalp anomalisinde, 4 odacık ve 4 kapağın görünümü ile büyük damar çıkışları normal olarak izlenebileceğinden antenatal taramada şimdi uygulanan kriterlerle bu anomali kolaylıkla atlanabilmektedir [1]. Doğumu takiben ark kesintisinin distaline kan akımının azalmasına bağlı olarak gelişen metabolik asidozun eşlik ettiği bir ölüm nerdeyse kaçınılmazdır. Genetik faktörler suçlansa da etyolojisi hala kesinlik kazanmamıştır [5]. Tanıda en önemli yöntemler fetal ekokardiyografi, iki boyutlu (2D) doppler ve 4D ultrasonografik analizdir. Olgu sunumumuzda prenatal tanı konan nadir görülen bir olgu olarak terme ulaşmış bir IAA olgusunu literatür 1şığında değerlendirmeyi amaçladık.

\section{OLGU}

31 yaşında G2P1 olan hasta başka bir merkezde takip olurken ikinci düzey ultrason değerlendirmesinde fetal kardiyak anomali saptanması üzerine hastanemize sevk edildi. Anne 24. gebelik haftasındayken tarafimızca yapılan fetal ekokardiyografide dört odacık kesitinde geniş inlet VSD izlendi (Resim 1). Sol ventriküler çıkış kesitinde geniş bir VSD ile birlikte aortanın hipoplazik olduğu saptandı (Resim 2). Üç damar-trakea kesitinde aortanın pulmoner artere kıyasla belirgin olarak hipoplazik olduğu gözlendi (Resim 3). Aortik ark kesiti elde edilmeye çalışıldığında asendan ve desendan aorta arasında devamlılık olmadığı, ayrıca çıkan aortanın innominate arter ve sol karotis kommunis ile devamlılik gösterdiği tespit edildi. Tanı IAA olarak değerlendirildi. Hastanın kişisel ve ailesel medikal öyküsünde herhangi bir özellik bulunmamaktaydı. Hasta bilgilendirilerek karyotip analizi önerildi. Ancak hasta invaziv test veya terminasyon seçeneklerini reddetti. Düzenli rutin bir şekilde antenatal takipler yapılarak gebelik terme kadar ulaştırıldı. Gebeliğinin 38. haftasında sezeryanla 3200 gr ağırlığında 1 dakika APGAR'1 7 olan canlı bir erkek bebek doğurdu. Doğum sonrasi pediyatrik kardiyoloji uzma$\mathrm{n} 1$ tarafindan yapilan fetal ekokardiyografi sonucu interrupted aortik ark, Tip B olarak raporlandi. Postnatal üçüncü günde opere edilen bebek postoperatif ikinci günde eksitus oldu.

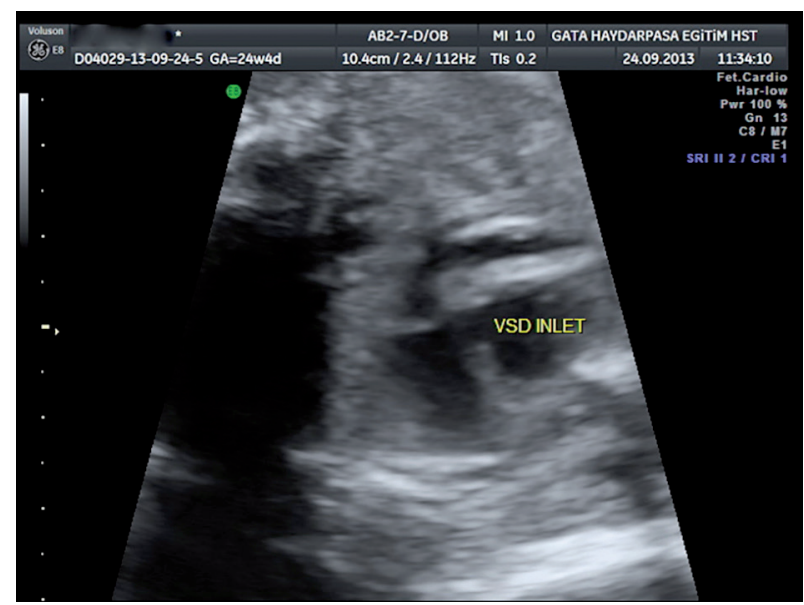

Resim 1. Fetal kalbin 4 odacık kesitinde geniş inlet ventriküler septal defektin (VSD) görünümü.

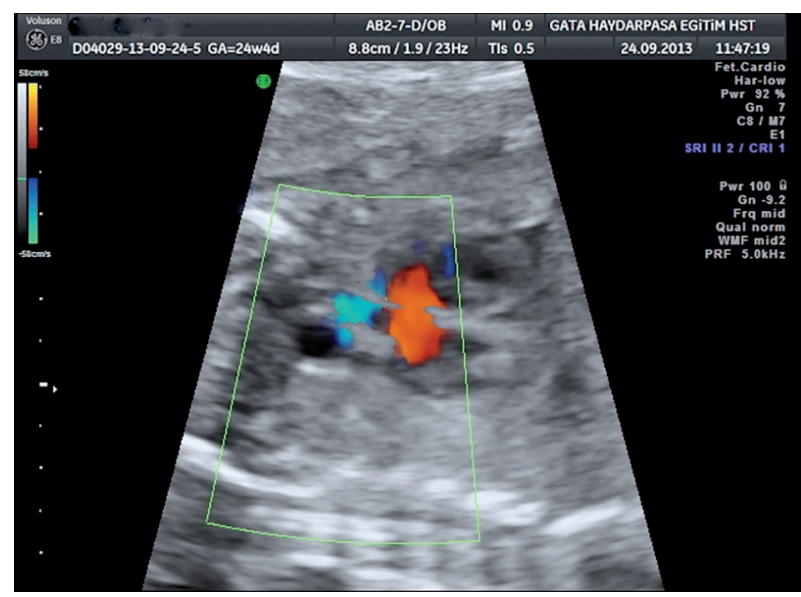

Resim 2. Sol ventriküler çıkışı kesitinde düz seyir gösteren içinde akım izlenen hipoplazik aort (Ao) ve geniş ventriküler septal defektin (VSD) görünümü.

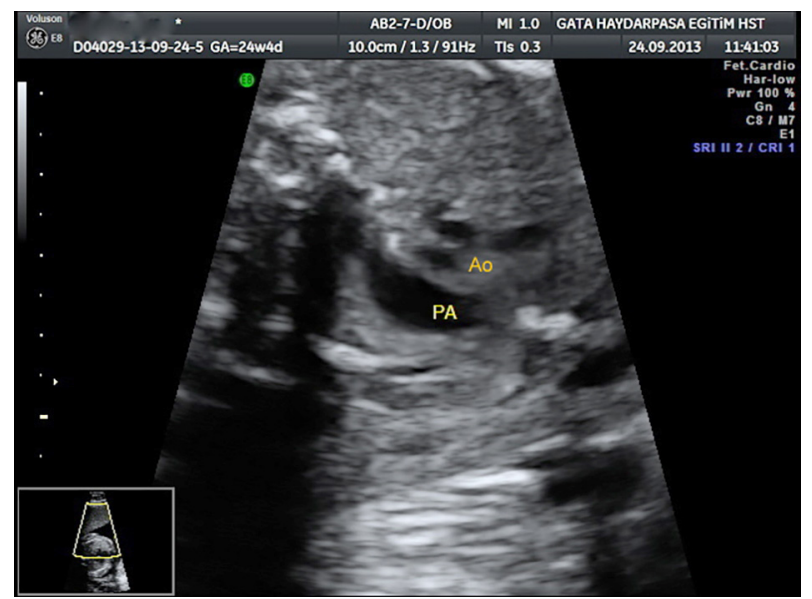

Resim 3. Üç damar kesitinde aortun (Ao) hipoplazik ve pulmoner arterin (PA) dilate görünümü. 


\section{TARTIŞMA}

Konjenital kalp hastalıklarının prenatal dönemde saptanabilme oranları \%5-45 arasında değişmektedir. Mevcut literatür bilgileri, fetal kardiyak anomali taramasının ilk trimester sonu ve erken ikinci trimesterde yapılmasını önermektedir. Dört odacık görünümüyle kıyaslandığında büyük damar çıkışlarının da taramaya eklenmesi tanı koyduruculuğu \%20-30 oranında artırmaktadır. Ancak bu tarama şekli bile IAA gibi bazı KKH'nın tanısının koyulmasina yetmemektedir [6]. Nitekim bizim vakamızda da hastada geniş bir VSD ve ASD olması sebebiyle tarafımıza refere edilmiş olup, IAA tanıs1 merkezimizde konmuştur. Yapılan bir çalışmada 14 yılda taranan $2520 \mathrm{KKH}$ içinde 15 'i Tip B ve 7'si Tip A olmak üzere toplam 22 adet (\%0.87) IAA tanısı konmuştur. Anne yaşı ortalama 24 olup, hastaların yarıdan fazlası 24 haftadan önce tanı almıştır. Vakaların yarısında FISH analizinde 22q11.2 mikrodelesyonu tespit edilmiştir. 24 haftadan önce tanınıp sonlandırılanlar hariç ameliyat şansı bulan 13 infantın 9'u ameliyat sonrası yaşamaktadır. Bütün vakalarda geniş VSD sol ventrikülün büyümesine müsade etmiş ve 4 odacık görüntüsünü normal kılmıştır [3]. Bizim olgumuzda anne yaşı 31 olup, 24. gebelik haftasından önce tanı konmuştur. Aileye konunun önemi ile ilgili detaylı bilgi verilmesine rağmen karyotip analizi yaptırmay1 istememeleri sebebiyle fetüsün genetik yapısı ile ilgili bilgi edinilememiştir.

Özellikle izole IAA Tip B'nin DiGeorge sendromu ve 22q11.2 mikrodelesyonuyla beraberliği mevcuttur. Yapılan bir çalışmada $53 \mathrm{KKH}$ olan 22q11.2 mikrodelesyonlu fetüslerin çoğunda (\%24.4) fallot tetralojisi ve ikinci sırada ise IAA (\%10.1) izlenmiştir [7]. 26 IAA tanısı almış fetüsün incelendiği bir seride bu anomalinin ana hatları küçük aort kapağıyla beraber normal boyutlarda sol ventrikül olarak belirlenmiştir. Aort kapağıyla pulmoner kapak arasında ya da aort ile pulmoner damar arasindaki boyut fark1 patognomonik olmasa da obstetrisyenin IAA ve aort koartasyonundan şüphelenmesi için önemli bulunmuştur [1]. Bizim olgumuzda da dört odacık görüntüsü normal olarak izlenmiş olup, geniş inlet VSD görülmesi sebebiyle yapılan ileri değerlendirme sonucunda IAA tanısı konmuştur. Tanıda ise B flow görüntüleme moduyla 4D ultrason her zaman iki boyutlu ultrasona üstündür. Ancak 2D ultrasona doppler akım eklenirse IAA tanısı rahatlıkla konulabilir. Prenatal konulan tanılar mutlaka doğum sonrası doğrulanmalıdır. Çünkü IAA tanısı konan fetüsler doğum sonrası tekrar değerlendildikten sonra aort koartasyonu tanısida alabilmektedirler [3].

Yüksek mortalite ve morbidite ile seyretmesi nedeni ile IAA erken tanı konulması gereken bir patolojidir. Doğal seyrine birakıldığında \%70-80 oranında doğum sonrası 1 aylık sürede ilerleyici kalp yetmezliği sebebiyle ölümle sonuçlanmaktadır [8]. Başka bir çalışmada ise doğum sonrası 8 tane müdahale edilmeyen hasta grubu 11 gün içinde ex olmuştur. Ancak opere edilen 453 hastanın 16 yıll1k takibi sonras $1 \% 23$ 'ü tekrar opere olarak hayatını sürdürmüş, \%59'u tekrar müdahaleye gerek kalmadan hayatta kalmış ve \%18 hasta ise eksitus olmuştur [9]. Ameliyat başarısı değelendirildiğinde ise risk faktörleri, düşük doğum ağırlığı, onarımın genç yaşta olması, Tip B IAA, küçük ve trabeküler bir VSD ve subaortik darlığın varlığıdır [9]. Yüksek frekanslı probların kullanımına bağlı olarak görüntü kalitesinin artmas1, fetal ekokardiyografinin tersiyer merkezlerde standart olarak kullanılması ve ultrason yapan obstetrisyenlerin artan deneyimleri bilhassa IAA gibi zor tanı alan KKH'larının daha erken ve yüksek başarıyla tanınmasını sağlamıştır $[2,10]$.

Sonuç olarak, erken ikinci trimesterde yapılan fetal kardiyak anomali taramasında, 4 odacık ve büyük damar çıkışlarına ek olarak görüntülenmesi zor olmayan 3 damar ve trakea görüntülenmesinin ilave edilmesiyle; aortik ark anomalileri, aberran sağ subklavain arter (ARSA) ve persiste sol vena kava süperior (PLSVC) gibi vasküler anomalilerin tan1S1 rahatlıkla koyulabilir. Bu sayede ciddi kardiyak defektlerin büyük çoğunluğunun erken zamanda saptanmasi sonucu bu olguların multidisipliner yaklaşımın sağlanabileceği tersiyer merkezlere yönlendirilmesi ile çok daha doğru ve uygun tedbirlerin alınması sağlanmış olacaktır.

\section{KAYNAKLAR}

1. Vogel M, Vernon MM, McElhinney DB, et al. Fetal diagnosis of interrupted aortic arch. Am J Cardiol 2010;105:727-734.

2. Axt-Fliedner R, Kawecki A, Enzensberger C, et al. Fetal and neonatal diagnosis of interrupted aortic arch: associations and outcomes. Fetal Diagn Ther 2011;30:299-305.

3. Volpe P, Tuo G, De Robertis V, et al. Fetal interrupted aortic arch: 2D-4D echocardiography, associations and outcome. Ultrasound Obstet Gynecol 2010;35:302-309. 
4. Schreiber C, Mazzitelli D, Haehnel JC, et al. The interrupted aortic arch: an overview after 20 years of surgical treatment. Eur J Cardiothorac Surg 1997;12:466-469.

5. Matsumoto T, Miyakoshi K, Yoshimura Y. Prenatal images of the truncus arteriosus with an interrupted aortic arch. Pediatr Cardiol 2013;34:473-475.

6. Sklansky MS, Berman DP, Pruetz JD, Chang RK. Prenatal screening for major congenital heart disease: superiority of outflow tracts over the 4-chamber view. J Ultrasound Med 2009;28:889-899.

7. Lee MY, Won HS, Baek JW, et al. Variety of prenatally diagnosed congenital heart disease in 22q11.2 deletion syndrome. Obstet Gynecol Sci 2014;57:11-16.
8. Takabayashi S, Shomura S, Yokoyama K, et al. Spontaneous closure of ductus arteriosus in interrupted aortic arch with ventricular septal defect. Jpn J Thorac Cardiovasc Surg 2004;52:98-100.

9. McCrindle BW, Tchervenkov CI, Konstantinov IE, et al. Risk factors associated with mortality and interventions in 472 neonates with interrupted aortic arch: a Congenital Heart Surgeons Society study. J Thorac Cardiovasc Surg $2005 ; 129: 343-350$.

10. Tezcan O, Güçlü O, Yazıcı S, et al. 14 years' experience of congenital heart disease in our cardiovascular clinic. Dicle Med J 2014;41:479-482. 